\title{
2d:4d, Big Fives and Aggression in Young Men of Caucasian, Ural and Asian Origin
}

\section{Victoria Rostovtseva}

Institute of Ethnology and Anthropology, Russian Academy of Sciences, Moscow

\section{Marina Butovskaya}

Russian State University for the Humanities, Moscow, Institute of Ethnology and Anthropology, Russian Academy of Sciences, Moscow, the National Research University Higher School of Economics, Moscow

\section{Ruzan Mkrtchjan}

Erevan University, Erevan

\begin{abstract}
According to modern views on human bio-sociality, Big Five personality traits have been shaped in the process of human evolution and their expression is an outcome of the complex interaction of prenatal predispositions and cultural environment. Present study investigates the impact of prenatal androgenization and cultural norms on the personality traits in adult men from four ethnic groups living on the territory of Russian Federation. The study was conducted on 263 young men (age range 17-30 years), including Russians, Armenians, ObUgric and Buryats. The results revealed significant population differences in 2D:4D ratios on both hands, with lowest ratios for Asian sample, increasing in populations to the West. Significant ethnic differences were found for Openness to New Experience, Conscientiousness, and Neuroticism. Positive association between 2D:4D ratios on the right hand and Agreeableness in men with no respect to population origin was detected. This relationship becomes stronger, when controlling for aggressiveness.
\end{abstract}

Social Evolution \& History, Vol. 18 No. 1, March 2019 110-126

(C) 2019 'Uchitel' Publishing House

DOI: $10.30884 / \mathrm{seh} / 2019.01 .06$ 


\section{INTRODUCTION}

Anthropologists, as well as cross-cultural psychologists, used to emphasize the cultural diversity and substantial impact of cultural institutions on individual psychology (Markus and Kitayama 1991). But numerous findings in evolutionary psychology and behavior genetics suggested much more complicated perspective (Bouchard and Loehlin 2001; Buss 1991; Eysenck 1990; Manning and Fink 2011; Loehlin 1991; Norenzayan and Heine 2005; Plomin et al. 1994). In line with them, the human nature and culture are interconnected. Universals in personality traits and behavior should not be ignored anymore.

The seminal work of McCrae and Costa (1997) conducted crossculturally reveal that personality trait structure is universal (although also see: Gurven et al., 2013). These authors concluded that 'common dimensions of personality may thus provide a framework for understanding cultural differences' (McCrae and Costa 1997: 509). Personality traits are 'biologically-based tendencies', and they should not be mixed with attitudes and values, representing 'culturally-influenced characteristic adaptations' (Allik and McCrae 2004: 25). Geographical grouping of cultures in scoring on values, as well as on self-reported personality traits were in similar directions (Schwartz 1999; Allik and McCrae 2004). European cultures in general score high in affective and intellectual autonomy, and Asian cultures are high in conservatism and hierarchy (Schwartz 1999), at the same time, Europeans score higher on Openness to New Experience (Allik and McCrae 2004). Besides, Southern European cultures tend to score higher on Neuroticism than Northern European cultures.

Numerous studies show basic sex differences in behavior and personality traits. Females perform better in verbal tasks and natural language, whereas males are better in spatial and mathematical areas (see review: Levy and Heller 1992). Males on average perform more physical aggression (Archer 2004; Baillargeon et al. 2007), and predisposed to make moral, utilitarian decisions, whereas females are more emotional (Fumagalli et al. 2010; Youssef et al. 2012). Great number of psychological survey studies provides evidence that women have higher scores on Neuroticism than men (Jorm 1987; Francis 1993; Lynn and Martin 1997, Butovskaya and Mkrtchan 2016). Previous research on Big Five personality traits and sex differences in 26 different cultures has revealed that women score significantly higher on both Agreeableness and Neuroticism scales (Costa et al. 2001). These results were later confirmed by other study in 55 different cultures (Schmitt et al. 2008). 
One of the most important sex hormones, which causes masculinization of human fetus, is testosterone $(\mathrm{T})$. $\mathrm{T}$ is known to be produced by Leydig cells, testicular members, which have two population peaks one at early prenatal stage and one at puberty. Human testis first becomes recognizable between $7^{\text {th }}$ and $8^{\text {th }}$ weeks of gestation with Leydig cells producing $\mathrm{T}$ from the $8^{\text {th }}$ week (Lee and Burger 1983). Research conducted by Codesal with colleagues on human aborted fetuses and stillborns showed that Leydig cells begin degenerate dramatically after 24th week of prenatal development with $\mathrm{T}$ level decreasing significantly up to the birth (Codesal et al. 1990). Human brain begins to differentiate near $9^{\text {th }}$ week of gestation (Rice and Barone 2000; Lan et al. 2000), thus the period of the T peak takes places at the time of early brain maturation, which plays important role in forming sexual dimorphism of human brain structures (Chi et al. 1977; Dubb et al. 2003; Cosgrove et al. 2007; Zuloaga et al. 2008).

Second to forth hand digits ratio (2D:4D) is known to be fine predictor of prenatal sex hormone exposure in humans (see review: Hönekopp et al. 2007). This ratio shows sexual dimorphism in adults (with higher values in females). Study of Malas with colleagues on aborted human fetuses revealed that sexual differences in 2D:4D ratio is observed as early as at the $9^{\text {th }}$ week of gestation (with ratio significantly higher in females) and remain consistent through gestational age (Malas et al. 2006). Several studies in humans report association between 2D:4D ratio after birth and the level of $\mathrm{T}$ and $\mathrm{E}$ in amniotic fluid during early prenatal development (Lutchmaya et al. 2004; Ventura et al. 2013). Although number of studies found no correlation between 2D:4D ratio and hormone concentration in umbilical cord directly after delivery (Hickey et al. 2010; Hollier et al. 2015), these findings cannot be interpreted as contradictive to results mentioned earlier, as umbilical cord method examine level of hormones in the late perinatal period, when $\mathrm{T}$ is significantly decreased compared to early prenatal levels. As has been reported 2D:4D ratio also shows no association with adult hormone levels (Hönekopp et al. 2007).

One of possible ways of assessing prenatal sex hormones influence on behavior is to estimate it within each sex separately, where variation in hormone levels (as well as in 2D:4D ratios and behavior patterns) are also present. Thus one of the most important challenges gender-specific socialization influence - can be eliminated. This has already been a focus of many studies, hypothesizing that the higher is $\mathrm{T}$ exposure during prenatal development - the more masculine are the features and behavior in both (or in any of the) sexes. Numerous stu- 
dies have been conducted, resulting in supporting evidence, for instance: verbal IQ and Agreeableness were positively correlated with 2D:4D ratio in both sexes, whereas numerical IQ showed negative correlation (Luxen and Buunk 2005), in several studies self-reported Physical Aggression was negatively associated with digit ratio in men and boys (Bailey and Hurd 2005; Hurd et al. 2011; Butovskaya et al. 2013). Other authors revealed positive correlation between digit ratio and Neuroticism in women (Fink et al. 2004) and in men (Butovskaya and Mkrtchjan 2016).

There is growing evidence that distribution of 2D:4D indexes over world human populations differs: Europeans have relatively high digit ratios both in men and in women (Manning and Fink 2011), African populations show broad variety of index values from very low (Zulus of South Africa, Igbos and Yorubas of Nigeria) (Manning et al. 2003; Gabriel et al. 2009) to almost of European level (Hadza of Tanzania) (Butovskaya et al. 2012, 2015). In the European part of Russia you can meet medium and high values, decreasing to the East in the people of Ural (Butovskaya et al. 2013). Asian populations on average may have the lowest 2D:4D indexes, it was stated in Japanese and Koreans (Peters et al. 2002; Wakabayashi and Nakazawa 2010; Hiraishi et al. 2012), but one should keep in mind that most of Asian studies have used indirect methods of measurement, which can provide lower digit ratio values (Manning et al. 2005). Also one of the studies comparing Caucasian and Asian 2D:4D ratios using indirect method did not find any significant differences between these groups, stating relatively high overall values (Hurd et al. 2011).

Direction of sex differences in digit ratio remains consistent all over the world.

Some researchers have already focused on cross-population comparison of personality traits with regard to national 2D:4D ratios. Manning and Fink have tested 23 European nations and US and revealed positive association between male national 2D:4D and average neuroticism (Manning and Fink 2011).

Goals of the present study are to compare populations and test the correlations between 2D:4D ratios and personality traits in adult men of different origin (the Caucasians, people of Ural and Asians). Based on the results of previous studies we will focus on aggression, agreeableness and neuroticism as the most probable candidates for association with digit ratios (and supposedly, prenatal androgenization) in men. 


\section{METHODS}

\section{Participants}

General male sample consisted of 263 men, 17-30 years of age. Among them 95 Armenians, 47 Russians, 70 Ob-Ugric and 51 Buryats.

The Buryats - are people of Southern Siberia, of Mongoloid origin. Nowadays most of them live in the Buryatian Republic of Russia (Baikal Lake area) - partly in urbanized environment of their native capital Ulan-Ude, and partly have traditional lifestyle in villages around (according to national population census 2010). Buryats are one of the few officially Buddhist peoples of Russia. In our sample majority of Buryats were temporally living in Moscow from 1 to 8 years.

Russians were mostly born in Moscow or nearby towns, with several exceptions.

Participants from these two groups had very heterogeneous professional activities and included both students of different specialties and people working in different fields.

Armenians are represented by students of humanitarian orientation, residents of Erevan (Armenia).

Ob-Ugric are people of Western Siberia, representatives of Ural race, transitional between Caucasians and Asians. They mostly live around Irtysh and $\mathrm{Ob}$ rivers in Khanty-Mansi Autonomous District. Our sample includes students of sports orientation, residents of Khanty-Mansiysk (Russia).

The overwhelming majority of our participants were single young men, with no children. All were native Russian speakers.

\section{D:4D measurements}

Measurements of the $2^{\text {nd }}$ and $4^{\text {th }}$ digits length were made on both hands, directly, using electronic caliper with precision of $0.01 \mathrm{~mm}$. We have measured the length from the basal crease to the tip of the finger without exerting pressure (Manning et al. 1998), if there was a band of the creases at the base of the digit - the most proximal one was used (Fink et al. 2004). Every digit was measured two times to reduce the error; finally we used the mean of two measurements. For various reasons digit measurements were not obtained from several participants, finally resulting in 246 subjects in general data set.

\section{Personality tests}

All subjects have completed two personality tests.

To assess aggressiveness we have applied Buss-Perry Aggression Questionnaire (AQ) (Buss and Perry 1992), which provides four subscales: physical aggression, verbal aggression, anger and hostility. 
The Big Five personality traits (Neuroticism, Extraversion, Openness to New Experience, and Agreeableness and Conscientiousness) were estimated through NEO Five-Factor Inventory (NEO-FFI) shortened version with 60 questions.

$\mathrm{AQ}$ and NEO-FFI were translated into Russian. The questionnaires we completed in the presence of experimenter.

All participants provided written consent to personal data processing and using it for scientific purposes. All methods and procedures were approved by Ethical Committee.

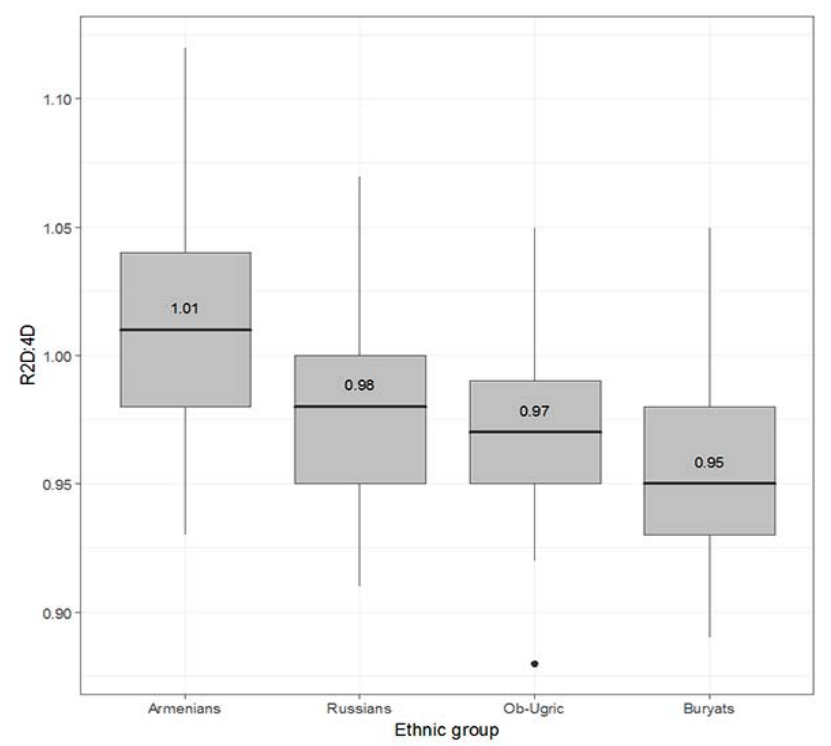

Fig. 1. Population differences in digit ratio indexes on the right hand

\section{RESULTS}

Statistical analysis was held in R Statistics. Population differences for each single trait were assessed trough One-way Analysis of Variance (ANOVA). One-way Analysis of Covariance (ANCOVA) was used to control for additional trait and test factor/covariate interaction. Interaction between factor and covariate was not detected in any case. To implement pairwise comparison for population differences we have used Tukey post hoc test. Relationship between 2D:4D and personality traits were assessed through linear regression. When using multiple linear regression (MLR) all predictors in question were tested for collinearity. Age distribution was highly skewed, thus age differences were estimated through Kruskal-Wallis test. 


\section{Population differences}

Differences between four study groups are summarized in Table 1 .

Table 1

Differences between four ethnic groups. Means displayed

\begin{tabular}{|c|c|c|c|c|c|c|c|c|c|c|c|c|c|}
\hline \multirow[b]{2}{*}{ مِ } & \multirow[b]{2}{*}{ Z } & \multirow[b]{2}{*}{ "ू. } & \multirow[b]{2}{*}{ 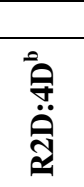 } & \multirow[b]{2}{*}{ 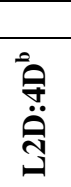 } & \multicolumn{4}{|c|}{ Aggression subscales } & \multicolumn{5}{|c|}{ NEO-FFI subscales } \\
\hline & & & & & $\ddot{\Sigma}$ & $\stackrel{4}{>}$ & 岁 & 岁 & 艺 & ix & 崩 & U & Zu \\
\hline $\begin{array}{l}\text { Arme- } \\
\text { nians }\end{array}$ & 95 & 19 & 1.01 & 1.00 & 26 & 16 & 17 & 23 & 21 & 29 & 29 & 27 & 32 \\
\hline $\begin{array}{l}\text { Rus- } \\
\text { sians }\end{array}$ & 47 & 25 & 0.98 & 0.98 & 20 & 15 & 14 & 20 & 18 & 28 & 31 & 26 & 28 \\
\hline $\begin{array}{l}\text { Ob- } \\
\text { Ugric }\end{array}$ & 70 & 20 & 0.97 & 0.97 & 25 & 15 & 16 & 21 & 20 & 28 & 26 & 26 & 32 \\
\hline $\begin{array}{l}\text { Bu- } \\
\text { ryats }\end{array}$ & 51 & 25 & 0.96 & 0.96 & 20 & 13 & 13 & 20 & 18 & 27 & 29 & 27 & 30 \\
\hline $\begin{array}{l}\text { Model } \\
\text { sum- } \\
\text { mary }\end{array}$ & & 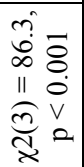 & 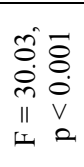 & 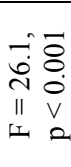 & 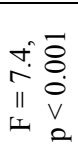 & 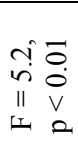 & 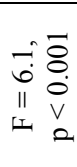 & 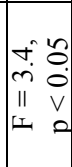 & $\stackrel{\dot{\leftrightarrow}}{=}$ & $\stackrel{\dot{\varphi}}{\dot{\theta}}$ & 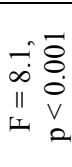 & $\stackrel{\dot{\leftrightarrow}}{g}$ & $\left|\begin{array}{cc}\infty & \ddots \\
\infty & 0 \\
r & 0 \\
11 & v \\
1 & 0\end{array}\right|$ \\
\hline
\end{tabular}

${ }^{a}$ Kruskal-Wallis test (displayed medians)

${ }^{\mathrm{b}}$ ANOVA test

${ }^{\mathrm{c}}$ ANCOVA test controlling for age

2D:4D ratios have demonstrated significant population differences $(p<0.001)$. Population 2D:4D on the right hand (R2D:4D) show predicted gradient with highest values in Armenians, followed by Russians and decreasing to the East with lowest values in Buryats. Armenians differ very significantly from all other given populations ( $p<0.001$ for all 3 cases), differences between Russians and Buryats can be treated as trend $(p=0.06)$, and Ugric population takes intermediate position between Russians and Buryats with no statistical significance in differences.

All four subscales of aggression have shown significant group differences $(\mathrm{p}<0.001)$.

Two subscales (Physical Aggression (PA), Anger (AN)) have revealed similar distribution across four groups (Fig. 2). Armenians and Ob-Ugric scored significantly higher $(p<0.0001$ in all cases) than Russians and Buryats for PA and AN. Although our samples were restricted to 17-30 years, groups have significant differences in average age within this interval, with much younger men in majority of 
Armenians and Ob-Ugric than in Russians and Buryats $(\mathrm{p}<0.001)$. Thus, population PA and AN differences could appear due to sample age differences. ANCOVA revealed that both age and ethnic group had significant general effects: for PA both age $(\mathrm{F}(1,216)=24.83)$ and group $(F(3,216)=7.43)$ effects were at $p<0.001$ (Fig. 3), whereas for AN group effect was much more significant $(\mathrm{F}(3,216)=6.13$, $p<0.001)$ than effect of age $(F(1,216)=6.46, p<0.05)$.
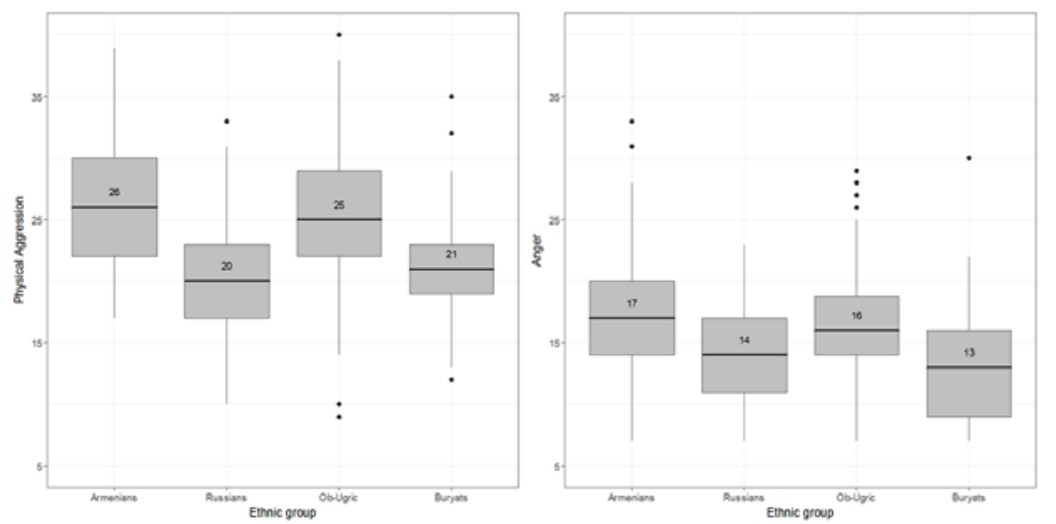

Fig. 2. Population differences in scores for physical aggression and anger
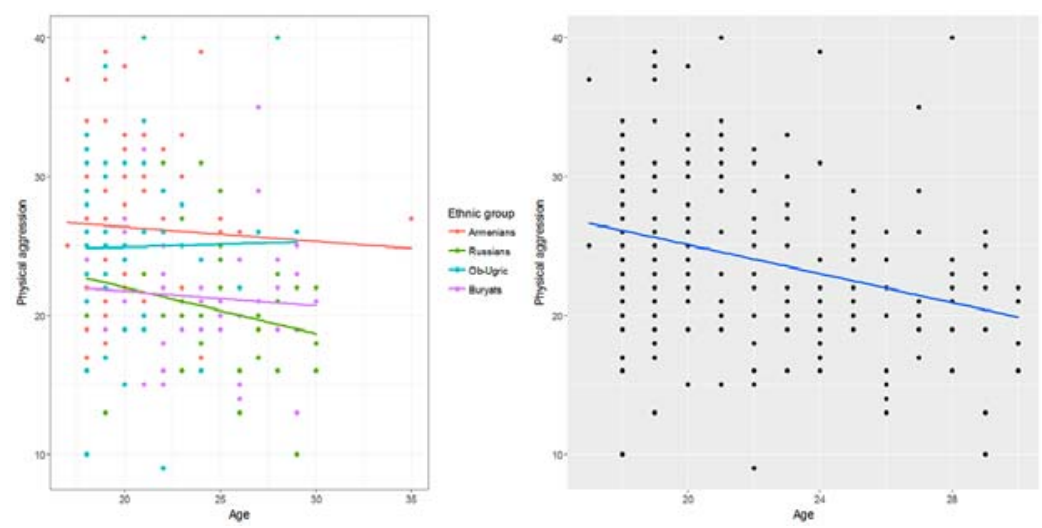

Fig. 3. Relationship between physical aggression and age: for each ethnic group (left) and in general sample (right) (SLR, R2 = 0.09, p $<0.001$ )

For Hostility (HT) subscale population means distribution looked similar to those for PA and AN, but statistically only Armenians had 
significantly higher scores for Hostility than Russians $(p=0.0019)$ and Buryats $(\mathrm{p}=0.0012)$. HT was more significantly influenced by age $(\mathrm{F}(1,216)=6.80, \mathrm{p}<0.01)$ than by ethnic group $(\mathrm{F}(3,216)=3.36$, $\mathrm{p}<0.05)$.

Verbal Aggression (VA) showed distribution of means across four populations similar to that of 2D:4D (Table 1). VA population differences were significant only for Buryats in comparison to Russians $(\mathrm{p}=0.0272)$, Ob-Ugric $(\mathrm{p}=0.0083)$ and Armenians $(\mathrm{p}<0.0001)$. Both group $(\mathrm{F}(3,216)=5.19)$ and age $(\mathrm{F}(1,216)=7.35)$ effects on VA were at $\mathrm{p}<0.01$.

The analysis of population differences in scores for NEO-FFI subscales revealed very significant difference for Openness to New Experience $(\mathrm{ONE})(\mathrm{p}<0.001)$, with weak positive effect of age $(\mathrm{F}(1,216)=5.836, \mathrm{p}<0.05)$. Ob-Ugric population provided significantly lower scores for ONE compared to Armenians $(p=0.0126)$, Buryats $(p=0.0079)$ and Russians $(p=0.0003)($ Tab. 1). Conscientiousness $(\mathrm{CN})$ subscale revealed weak population differences $(\mathrm{p}<0.05)$, with Russians providing significantly lower scores than Armenians $(p=0.0091)$ and Ob-Ugric $(p=0.0352)$. There was no age effect for CN subscale. Neuroticism (NT) had the highest scores in Armenians, but this result reached statistical significance only when comparing Armenians and Russians $(\mathrm{p}=0.012)$, whose scores on NT differed considerably. Armenians and Russians also differed significantly in age, with Armenians younger on average. NT showed weak negative association with age (Simple Linear Regression $(\mathrm{SLR}), \mathrm{F}(1,222)=3.93$, $\mathrm{R} 2=0.08, \mathrm{~B}=-0.276, \mathrm{p}<0.05)$. Thus it is still difficult to derive certain conclusion, which factor played more important role in NT differences - age or ethnic group. Agreeableness and Extraversion were neither associated with ethnic group, nor with age.

\section{D:4D ratios and psychological traits}

Values of tested variables were transformed to Z-scores for each population, and pooled for analysis. Thus we have analyzed not the absolute value of the trait, but its deviation from population mean. This approach allows eliminating noise of general population differences.

SLR revealed only one positive relationship: Agreeableness (NEO-FFI) was predicted by R2D:4D, but with low predictable power $(\mathrm{F}(1,238)=5.098, \mathrm{~B}=0.144, \mathrm{R} 2=0.02, \mathrm{p}=0.025, \mathrm{~N}=239)$ (Fig. 4, left). This effect was also consistent in all four groups separately (Fig. 4, right). 

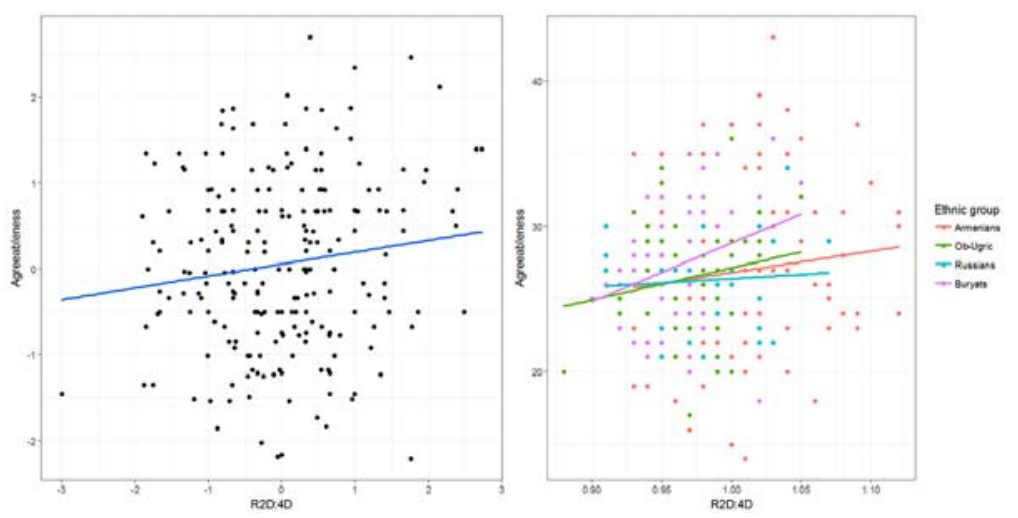

Fig. 4. Relationship between digit ratios on the right hand and agreeableness in general sample (left)

(SLR, R2 = 0.02, p = 0.025), and for each ethnic group (right)

None of aggression subscales, as well as general aggression, showed any paired correlation with digit ratios on both hands.

MLR revealed significant relationship between Agreeableness and R2D:4D controlling for general aggression $(F(2,233)=10.87, \mathrm{R} 2=$ $0.085, \mathrm{p}<0.001)$, with positive effect of digit ratios $(\mathrm{B}=0.143$, $p=0.023)$ and negative effect of aggression $(B=-0.252, p<0.001)$ (Fig. 5). Two aggression subscales basically contributed to this relationship, which can be demonstrated in model with three predictors: Agreeableness is predicted by Verbal Aggression, 2D:4D and Hostility $(\mathrm{F}(3,232)=10.23, \mathrm{R} 2=0.12, \mathrm{p}<0.001)(\mathrm{Tab} .2)$.
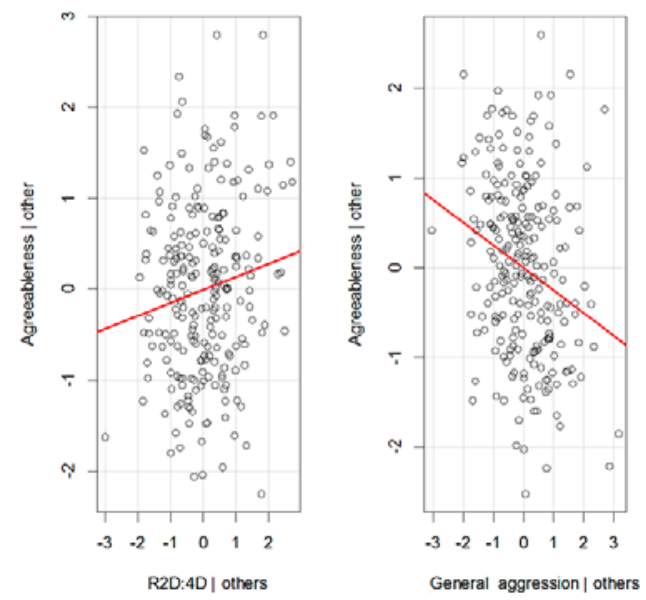

Fig. 5. Added-variable plot for agreeableness predicted by digit ratios on the right hand and general aggression (MLR, R2 $=0.085, \mathrm{p}<0.001$ ) 
Table 2

Multiple linear regression. Agreeableness (NEO-FFI) is predicted by digit ratios on the right hand (R2D:4D), hostility and verbal aggression (Buss-Perry AQ)

\begin{tabular}{|c|l|c|c|}
\hline $\begin{array}{c}\text { Dependent } \\
\text { Variable }\end{array}$ & \multicolumn{1}{|c|}{ Predictors } & $\begin{array}{c}\text { Regression } \\
\text { coefficient }\end{array}$ & P-value (sig.) \\
\hline Agreeableness & Hostility & -0.132 & 0.044 \\
\cline { 2 - 4 } & R2D:4D & 0.160 & 0.0098 \\
\cline { 2 - 4 } & Verbal aggression & -0.228 & 0.0004 \\
\hline
\end{tabular}

$\mathrm{F}(3,232)=10.23, \mathrm{R}^{2}=0.12, \mathrm{p}<0.001$

All correlations of personality traits with each other are represented in Table 3.

Table 3

Relationship between personality traits in general male sample

\begin{tabular}{|c|c|c|c|c|c|c|c|c|c|}
\hline & 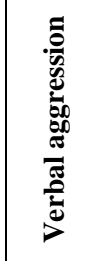 & 总 & 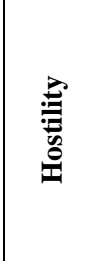 & 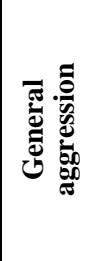 & 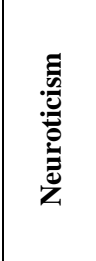 & 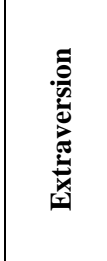 & 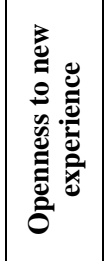 & 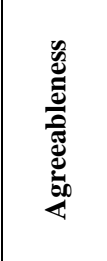 & 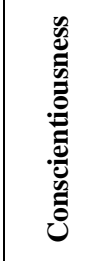 \\
\hline $\begin{array}{l}\text { Physical } \\
\text { aggression }\end{array}$ & $0.47^{* * *}$ & $0.55^{* * *}$ & $0.41^{* * *}$ & $0.79^{* * *}$ & $0.26^{* * *}$ & 0.06 & $-0.22^{* *}$ & -0.14 & 0.00 \\
\hline $\begin{array}{l}\text { Verbal } \\
\text { aggression }\end{array}$ & & $0.39^{* * *}$ & $0.41^{* * *}$ & $0.69^{* * *}$ & 0.11 & 0.00 & 0.02 & $-0.26^{* * *}$ & 0.04 \\
\hline Anger & & & $0.56^{* * *}$ & $0.82^{* * *}$ & $0.44^{* * *}$ & -0.04 & -0.10 & -0.14 & $-0.22^{* *}$ \\
\hline Hostility & & & & $0.77^{* * * *}$ & $0.53^{* * *}$ & -0.11 & 0.02 & $-0.19^{*}$ & $-0.18^{*}$ \\
\hline \begin{tabular}{|l|} 
General \\
aggression
\end{tabular} & & & & & $0.46^{* * *}$ & -0.02 & -0.08 & $-0.22^{* *}$ & -0.13 \\
\hline \begin{tabular}{|l|} 
Neuroti- \\
cism
\end{tabular} & & & & & & $-0.30^{* * * *}$ & -0.11 & -0.07 & $-0.36^{* * *}$ \\
\hline $\begin{array}{l}\text { Extraver- } \\
\text { sion }\end{array}$ & & & & & & & 0.14 & 0.00 & $0.26^{* * *}$ \\
\hline \begin{tabular}{|l|} 
Openness \\
to new ex- \\
perience
\end{tabular} & & & & & & & & -0.01 & 0.12 \\
\hline $\begin{array}{l}\text { Agree- } \\
\text { ableness }\end{array}$ & & & & & & & & & 0.09 \\
\hline
\end{tabular}

Pearson's correlation coefficients for all pairwise correlations, Bonferroni corrected. Correlations marked ${ }^{*} \mathrm{P}<0.05,{ }^{* *} \mathrm{P}<0.01,{ }^{* * *} \mathrm{P}<0.001 ; \mathrm{N}=261$. 


\section{DISCUSSION}

Our findings on population 2D:4D ratios differences support other data showing low average values for Asian populations (Peters et al. 2002; Wakabayashi and Nakazawa 2010; Hiraishi et al. 2012), increasing in the populations to the West (Manning and Fink 2011; Butovskaya et al. 2013). Still we do not know whether these differences appeared due to genetic variation between populations in question, or they were a result of epigenetic environmental impact. These questions are opened for further investigation. More data for Asian populations should be provided in the future using direct method of measurement to come to more sound comparative conclusions.

All aggression subscales were subjects to more or less significant negative age effect, with strongest for Physical Aggression (Fig. 3). From one side these results are somewhat controversial to large scale longitudinal study revealing stability of aggressive traits over lifespan (Huesmann et al. 1984), on the other hand there is also some evidence, that aggressive behaviors may decrease with age (Toldos 2005). Males in all four cultures expressed more aggressive behaviors at the ages closer to puberty, than in more mature ages and these data are well associated with idea of young male syndrome (Wilson and Daly 1985), demonstrated both for humans and many nonhuman primate species. Physical Aggression and Anger show high collinearity, whereas Hostility and Verbal Aggression have different distributions. This finding corresponds to previous evidence that Physical Aggression and Anger have common genetic basis, different from that of Hostility (Manuck et al. 1999). Differences in Physical Aggression and Anger between four studied groups were highly significant, but provided pattern, which did not match population digit ratios means distribution, whereas matched perfectly samples age differences. Since both age and ethnic group effects appeared significant for Physical Aggression and Anger, it is still difficult to derive any certain conclusion about the nature of observed pattern.

In our study, significant ethnic differences were found for Openness to New Experience (highest in Russians), Conscientiousness (lowest in Russians), and Neuroticism (Armenians scoring higher than others). This was generally in line with earlier conclusions of McCrae with co-authors (McCrae et al. 2005: 410), that 'European cultures differ systematically from Asian and African cultures, chiefly with respect Openness to New Experience scores, on which Europeans score higher. Southern European cultures tend to score higher on Neuroticism than Northern European cultures.

We have not found correlations of 2D:4D ratios and any of the aggression subscales. Although there is a number of studies revealing 
such kind of correlation (Bailey and Hurd 2005; Hurd et al. 2011; Butovskaya et al. 2013), some also fail to (Butovskaya et al. 2012). We suspect that such controversy in findings may also appear due to age effects, which may result in non-linear relationship between aggression and 2D:4D even in more-or-less standard age samples (18-30 years). We would recommend conducting similar studies with more accurate age limitations.

Digit ratios at the right hand have shown association with only one personality trait - Agreeableness, universally over four groups (Fig. 4). R2D:4D effect explains around 2 per cent of Agreeableness variation. Such low predictability is not much surprising: human personality and behavior traits are such complex phenomena, that one can hardly assume that any of them can be sufficiently determined by a single factor, thus something around 2 per cent is already the evidence. Our findings correspond to previous report of Luxen and Buunk, who also have observed positive association of R2D:4D and self-reported Agreeableness within both sexes using the same direct method of digit ratios measurement (Luxen and Buunk 2005). However, Fink with colleagues have reported negative correlation in women, whereas in men correlation was positive but not significant (Fink et al. 2004). This subject requires further investigation, but it may be hypothesized that the level of Agreeableness shows highest values in people with medium 2D:4D ratios across both sexes, such medium values may be quite high for males and quite low for females.

Besides, our study has revealed that males with lower R2D:4D tend to be less agreeable and more aggressive by self-reports. R2D:4D and aggressiveness explains around 10 per cent of Agreeableness variation, which is quite high for such kind of relationship (Fig. 4).

We have not found significant association of Neuroticism with digit ratios. Nevertheless, our results do not contradict findings of Manning and Fink that nations with high male 2D:4D ratios have high scores for Neuroticism (Manning and Fink 2011). In our study Armenians, who had significantly higher 2D:4D ratios than any other given population also had the highest mean values for Neuroticism.

Ob-Ugric population in our study scored significantly lower on Openness to New Experience than all other ethnic groups (Table 1). Important limitations on this finding is that Buryats in our study were Moscow residents: meaning that these individuals needed to be opened to new experience enough to venture to leave their native lands for capital city. Probably, Buryats would score much lower if they were native-land people. The weak age effect also can play role in forming this kind of pattern.

Further research is required for amplification of obtained results. 


\section{ACKNOWLEDGEMENTS}

We are grateful to Yulia Fedenok and Daria Dronova for support with data collection, and to Ido Pen for expert opinion on statistical analysis. Many thanks to our anonymous respondents participating in this study. This study was supported by RFBR grant № 17-29-02203, and conducted within the scope of the program of fundamental studies of the National Research University Higher School of Economics (MB).

\section{REFERENCES}

Allik, J. and McCrae, R. R. 2004. Toward a Geography of Personality Traits. Journal of Cross-Cultural Psychology 35 (1): 13-28.

Archer, J. 2004. Sex Differences in Aggression in Real-world Settings: A MetaAnalytic Review. Review of General Psychology 8 (4): 291.

Bailey, A. A., and Hurd, P. L. 2005. Finger Length Ratio (2D: 4D) Correlates with Physical Aggression in Men but not in Women. Biological Psychology 68 (3): 215-222.

Baillargeon, R. H., Zoccolillo, M., Keenan, K., Côté, S., Pérusse, D., Wu, H. X., ..., and Tremblay, R. E. 2007. Gender Differences in Physical Aggression: A Prospective Population-based Survey of Children before and after 2 Years of Age. Developmental Psychology 43 (1): 13.

Bouchard, T. J. and Loehlin, J. C. 2001. Genes, Evolution, and Personality. Behavior Genetics 31 (3): 243-273.

Buss, A. H., and Perry, M. 1992. The Aggression Questionnaire. J PersSoc Psychol 63: 452-459.

Buss, D. M. 1991. Evolutionary Personality Psychology. Annual Review of Psychology 42(1): 459-491.

Butovskaya, M., Burkova, V., Karelin, D., and Fink, B. 2015. Digit Ratio (2D: 4D), Aggression, and Dominance in the Hadza and the Datoga of Tanzania. American Journal of Human Biology 27 (5): 620-627.

Butovskaya, M., Fedenok, J., Burkova, V., and Manning, J. 2013. Sex Differences in 2D: 4D and Aggression in Children and Adolescents from Five Regions of Russia. American Journal of Physical Anthropology 152 (1): 130-139.

Butovskaya, M., and Mkrtchjan, R. 2016. 2D:4D and Personality Features in Armenian Students: Gender Differences. Vestnik Moscovskogo Universiteta. Seriya 23, Anthropology 1: 76-85.

Butovskaya, M. L., Vasilyev, V. A., Lazebny, O. E., Burkova, V. N., Kulikov, A. M., Mabulla, A., ... and Ryskov, A. P. 2012. Aggression, Digit Ratio, and Variation in the Androgen Receptor, Serotonin Transporter, and Dopamine D4 Receptor Genes in African Foragers: the Hadza. Behavior Genetics 42 (4): 647-662.

Chi, J. G., Dooling, E. C., and Gilles, F. H. 1977. Left-Right Asymmetries of the Temporal Speech Areas of the Human Fetus. Archives of Neurology 34 (6): 346-348

Codesal, J., Regadera, J., Nistal, M., Regadera-Sejas, J., and Paniagua, R. 1990. Involution of Human Fetal Leydigcells. Animmunohistochemical, Ultrastructural and Quantitative Study. Journal of Anatomy 172: 103. 
Cosgrove, K. P., Mazure, C. M., and Staley, J. K. 2007. Evolving Knowledge of Sex Differences in Brain Structure, Function, and Chemistry. Biological Psychiatry 62 (8): 847-855.

Costa Jr. P., Terracciano, A., and McCrae, R. R. 2001. Gender Differences in Personality Traits Across Cultures: Robust and Surprising Findings. Journal of personality and social psychology 81(2): 322 .

Dubb, A., Gur, R., Avants, B., and Gee, J. 2003. Characterization of Sexual Dimorphism in the Human Corpus Callosum. Neuroimage 20 (1): 512-519.

Eysenck, H. J. 1990. Genetic and Environmental Contributions to Individual Differences: The Three Major Dimensions of Personality. Journal of Personality 58 (1): 245-261.

Fink, B., Manning, J. T., and Neave, N. 2004. Second to Fourth Digit Ratio and the 'Big Five' Personality Factors. Personality and Individual Differences 37 (3): 495-503.

Francis, L. J. 1993. The Dual Nature of the Eysenckian Neuroticism Scales: A Question of Sex Differences? Personality and Individual Differences 15 (1): 43-59.

Fumagalli, M., Vergari, M., Pasqualetti, P., Marceglia, S., Mameli, F., Ferrucci, R., ... and Barbieri, S. 2010. Brain Switches Utilitarian Behavior: Does Gender Make the Difference? PLoSOne, 5 (1), e8865.

Gabriel, S. O., Hakeem, B. F., Ezon-Ebidor, I. E., Emeka, A. O., and Kenneth, S. O. 2009. Second to Fourth Digit Ratio in Nigerian Igbos and Yorubas. Scientific Research and Essays 4 (10): 1146-1148.

Gurven, M., Von Rueden, C., Massenkoff, M., Kaplan, H., Lero Vie, M. 2013. How universal is the Big Five? Testing the five-factor model of personality variation among forager-farmers in the Bolivian Amazon. Journal of personality and social psychology 104 (2): 354.

Hickey, M., Doherty, D. A., Hart, R., Norman, R. J., Mattes, E., Atkinson, H. C., and Sloboda, D. M. 2010. Maternal and Umbilical Cord Androgen Concentrations Do not Predict Digit Ratio (2D: 4D) in Girls: A Prospective Cohort Study. Psychoneuroendocrinology 35 (8): 1235-1244.

Hiraishi, K., Sasaki, S., Shikishima, C., and Ando, J. 2012. The Second to Fourth Digit Ratio (2D: 4D) in a Japanese Twin Sample: Heritability, Prenatal Hormone Transfer, and Association with Sexual Orientation. Archives of Sexual Behavior 41 (3): 711-724.

Hollier, L. P., Keelan, J. A., Jamnadass, E. S., Maybery, M. T., Hickey, M., and Whitehouse, A. J. 2015. Adult Digit Ratio (2D: 4D) Is not Related to Umbilical Cord Androgen or Estrogen Concentrations, their Ratios or Net Bioactivity. Early Human Development 91 (2): 111-117.

Hönekopp, J., Bartholdt, L., Beier, L., and Liebert, A. 2007. Second to Fourth Digit Length Ratio (2D:4D) and Adult Sex Hormone Levels: New Data and a MetaAnalytic Review. Psychoneuroendocrinology 32 (4): 313-321.

Huesmann, L. R., Eron, L. D., Lefkowitz, M. M., and Walder, L. O. 1984. Stability of Aggression over Time and Generations. Developmental Psychology 20 (6): 1120

Hurd, P. L., Vaillancourt, K. L., and Dinsdale, N. L. 2011. Aggression, Digit Ratio and Variation in Androgen Receptor and Monoamine Oxidase: A genes in Men. Behaviorgenetics 41 (4): 543-556. 
Jorm, A. F. 1987. Sex Differences in Neuroticism: A Quantitative Synthesis of Published Research. Australian and New Zealand Journal of Psychiatry 21 (4): 501-506.

Lan, L. M., Yamashita, Y., Tang, Y., Sugahara, T., Takahashi, M., Ohba, T., and Okamura, H. 2000. Normal Fetal Brain Development: MR Imaging with a Half-Fourier Rapid Acquisition with Relaxation Enhancement Sequence 1. Radiology 215 (1): 205-210.

Lee, V. W. K., and Burger, H. G. 1983. Pituitary Testicular Axis during Pubertal Development. The Pituitary and Testis. Monographs on Endocrinology 25: 44-70. Springer Berlin Heidelberg.

Levy, J., and Heller, W. 1992. Gender Differences in Human Neuropsychological Function. Sexual Differentiation 11: 245-274. New York: Springer US.

Loehlin, J. C. 1992. Genes and Environment in Personality Development. Newbury Park, CA: Sage Publications, Inc.

Lutchmaya, S., Baron-Cohen, S., Raggatt, P., Knickmeyer, R., and Manning, J. T. 2004. $2^{\text {nd }}$ to $4^{\text {th }}$ Digit Ratios, Fetal Testosterone and Estradiol. Early Human Development 77 (1): 23-28.

Luxen, M. F., and Buunk, B. P. 2005. Second-to-Fourth Digit Ratio Related to Verbal and Numerical Intelligence and the Big Five. Personality and Individual Differences 39 (5): 959-966.

Lynn, R., and Martin, T. 1997. Gender Differences in Extraversion, Neuroticism, and Psychoticism in 37 Nations. The Journal of Social Psychology 137 (3): 369-373.

Malas, M. A., Dogan, S., Evcil, E. H., and Desdicioglu, K. 2006. Fetal Development of the Hand, Digits and Digit Ratio (2D: 4D). Early Human Development 82 (7): 469-475.

Manning, J. T., Henzi, P., Venkatramana, P., Martin, S., and Singh, D. 2003. Second to Fourth Digit Ratio: Ethnic Differences and Family Size in English, Indian and South African Populations. Annals of Human Biology 30 (5): 579-588.

Manning, J. T., and Fink, B. 2011. Digit Ratio (2D: 4D) and Aggregate Personality Scores Across Nations: Data from the BBC Internet Study. Personality and Individual Differences 51 (4): 387-391.

Manning, J. T., Scutt, D., Wilson, J., and Lewis-Jones, D. I. 1998. The Ratio of $2^{\text {nd }}$ to $4^{\text {th }}$ Digit Length: A Predictor of Sperm Numbers and Concentrations of Testosterone, Luteinizing Hormone and Oestrogen. Human Reproduction 13 (11): 3000-3004.

Manning, J. T., Fink, B., Neave, N., and Caswell, N. 2005. Photocopies Yield Lower Digit Ratios (2D: 4D) than Direct Finger Measurements. Archives of Sexual Behavior 34 (3): 329-333.

Manuck, S. B., Flory, J. D., Ferrell, R. E., Dent, K. M., Mann, J. J., and Muldoon, M. F. 1999. Aggression and Anger-Related Traits Associated with a Polymorphism of the Tryptophan Hydroxylase Gene. Biological Psychiatry 45 (5): 603-614.

Markus, H. R., and Kitayama, S. 1991. Culture and the Self: Implications for Cognition, Emotion, and Motivation. Psychological Review 98 (2): 224.

McCrae, R. R., and Costa Jr, P. T. 1997. Personality trait structure as a human universal. American psychologist 52 (5): 509. 
McCrae, R. R., and Terracciano, A. 2005. Personality Profiles of Cultures: Aggregate Personality Traits. Journal of Personality and Social Psychology 89 (3): 407-425.

Norenzayan, A. and Heine, S.J. 2005. Psychological Universals: What Are They and How Can We Know? Psychological Bulletin 131 (5): 763.

Peters, M., Tan, Ü., Kang, Y., Teixeira, L., and Mandal, M. 2002. Sex-specific Finger-Length Patterns Linked to Behavioral Variables: Consistency Across Various Human Populations. Perceptual and Motor Skills 94 (1): 171-181.

Plomin, R., Owen, M. J., and McGuffin, P. 1994. The Genetic Basis of Complex Human Behaviors. Science 264: 1733-1733.

Rice, D., and Barone Jr, S. 2000. Critical Periods of Vulnerability for the Developing Nervous System: Evidence from Humans and Animal Models. Environmental Health Perspectives 108 (Suppl. 3): 511.

Schmitt, D. P., Realo, A., Voracek, M., and Allik, J. 2008. Why Can't a Man Be More Like a Woman? Sex Differences in Big Five Personality Traits Across 55 Cultures. Journal of Personality and Social Psychology 94 (1): 168.

Schwartz S. H. 1999. A theory of cultural values and some implications for work Applied psychology 48 (1): 23-47.

Toldos, M. P. 2005. Sex and Age Differences in Self-Estimated Physical, Verbal and Indirect Aggression in Spanish Adolescents. Aggressive Behavior 31 (1): 13-23.

Ventura, T., Gomes, M. C., Pita, A., Neto, M. T., and Taylor, A. 2013. Digit Ratio (2D: 4D) in Newborns: Influences of Prenatal Testosterone and Maternal Environment. Early Human Development 89 (2): 107-112.

Wakabayashi, A., and Nakazawa, Y. 2010. On Relationships between Digit Ratio (2D: 4D) and Two Fundamental Cognitive Drives, Empathizing and Systemizing, in Japanese Sample. Personality and Individual Differences 49 (8): 928-931.

Wilson, M. and Daly, M. 1985. Competitiveness, Risk Taking, and Violence: The Young Male Syndrome. Ethology and Sociobiology 6 (1): 59-73.

Youssef, F. F., Dookeeram, K., Basdeo, V., Francis, E., Doman, M., Mamed, D., ... and Legall, G. 2012. Stress Alters Personal Moral Decision Making. Psychoneuroendocrinology 37 (4): 491-498.

Zuloaga, D. G., Puts, D. A., Jordan, C. L., and Breedlove, S. M. 2008. The Role of Androgen Receptors in the Masculinization of Brain and: What We've Learned from the Testicular Feminization Mutation. Hormones and Behavior 53 (5): 613-626. 